\title{
Thorium based fuel loading pattern for PWR reactor
}

\author{
Mikolaj Oettingen ${ }^{1, *}$ \\ ${ }^{1}$ AGH University of Science and Technology, Faculty of Energy and Fuels, Department of Nuclear \\ Energy, al. Mickiewicza 30, 30-059, Krakow, Poland
}

\begin{abstract}
The Monte Carlo Continuous Energy Burnup Code was used for numerical simulations of the pressurized water reactor (PWR) with mixed U-Th fuel. The thorium fuel was introduce to the core of the Westinghouse 4-loop PWR in order to investigate the time evolutions of fissile ${ }^{233} \mathrm{U},{ }^{235} \mathrm{U}$, ${ }^{239} \mathrm{Pu},{ }^{241} \mathrm{Pu}$ and of fertile ${ }^{232} \mathrm{Th}$ and ${ }^{238} \mathrm{U}$. The core loading pattern was designed using the Whole Assembly Seed and Blanket (WASB) approach. The following calculations show the feasibility of the proposed incore fuel management patter using the available numerical tools, developed numerical model and methods.
\end{abstract}

\section{Introduction}

The Monte Carlo Continuous Energy Burnup Code (MCB) developed at the Department of Nuclear Energy, Faculty of Energy and Fuels of the AGH University of Science and Technology, Krakow, Poland was applied for the creation of a full scale numerical model of the Pressurized Water Reactor (PWR) [1,2]. The functionalities of the code allow application of the various core loading patterns with different types of nuclear fuel. In the study I have introduced thorium fuel into the matrix of the Westinghouse 4-loop PWR in order to investigate time evolutions of fissile ${ }^{233} \mathrm{U},{ }^{235} \mathrm{U},{ }^{239} \mathrm{Pu},{ }^{241} \mathrm{Pu}$ and fertile ${ }^{232} \mathrm{Th}$ and ${ }^{238} \mathrm{U}$ [3]. The thorium was introduced into the reactor core in the form of separate fuel assemblies (FA). This heterogenous approach is called Whole Assembly Seed and Blanket (WASB) [4]. The seed assemblies provide surplus neutron for effective conversion of the fertile ${ }^{232} \mathrm{Th}$ to the fissile ${ }^{233} \mathrm{U}$ in the blanket assemblies. The thorium fuel cycle shows numerous advantages over uranium fuel cycle and could complement it in the near future [5, 6].

The commercial nuclear reactors operate on the U-Pu fuel cycle. In this cycle the fresh nuclear fuel contains either natural or low enriched uranium (up to $5 \%$ fissile ${ }^{235} U$ ) in the oxide form. ${ }^{235} \mathrm{U}$ is the main fissile isotope responsible for about $60 \%$ of fission events, while remaining ${ }^{238} \mathrm{U}$ serves as a fertile material for breeding of fissile ${ }^{239} \mathrm{Pu}$. As it is shown in Eq. 1 , the radiative neutron capture on ${ }^{238} \mathrm{U}$ follows to two $\beta^{-}$decays and finally to the production of fissile ${ }^{239} \mathrm{Pu}$. The ${ }^{239} \mathrm{Pu}$ produced from ${ }^{238} \mathrm{U}$ contributes to about $30 \%$ of fission events over fuel lifetime. The remaining $10 \%$ of fissions events occurs on ${ }^{238} \mathrm{U},{ }^{241} \mathrm{Pu}$ and on bred minor actinides i.e. isotopes of $\mathrm{Np}, \mathrm{Am}$ and $\mathrm{Cm}$. The uranium fuel cycle have been the starting point for the civil and military applications of nuclear technologies because ${ }^{235} \mathrm{U}$ is the only fissile

\footnotetext{
* Corresponding author: moettin@agh.edu.pl
} 
isotopes occurring in nature. In the Th-U fuel cycle the fertile ${ }^{232} \mathrm{Th}$ plays the analogues role like the ${ }^{238} \mathrm{U}$ in $\mathrm{U}-\mathrm{Pu}$ fuel cycle. It converts to the fissile ${ }^{233} \mathrm{U}$ on the neutron capture and two following $\beta$ - decays, as it is shown in Eq.2.

$$
\begin{aligned}
& n+{ }_{92}^{238} U \rightarrow{ }_{92}^{239} U \stackrel{\beta^{-}(23.5 \mathrm{~min})}{\longrightarrow}{ }_{93}^{239} \mathrm{~Np} \stackrel{\beta^{-}(2.35 \mathrm{~d})}{\longrightarrow}{ }_{94}^{239} \mathrm{Pu} \\
& n+{ }_{90}^{232} \mathrm{Th} \rightarrow{ }_{90}^{233} \mathrm{Th} \stackrel{\beta^{-}(22 \mathrm{~min})}{\longrightarrow}{ }_{91}^{233} \mathrm{~Pa} \stackrel{\beta^{-}(27 \mathrm{~d})}{\longrightarrow}{ }_{92}^{233} \mathrm{U}
\end{aligned}
$$

The conversion mechanism is similar but it takes longer time to produce fissile ${ }^{233} \mathrm{U}$ due to the longer half-life time of ${ }^{233} \mathrm{~Pa}$ (27 days). The major difference comparing to U-Pu fuel cycle is the lack of the naturally occurring fissile isotopes of thorium. Therefore, the initial neutrons for breeding of ${ }^{233} \mathrm{U}$ are provided either by ${ }^{235} \mathrm{U}$ or by ${ }^{239} \mathrm{Pu}$. The ${ }^{233} \mathrm{U}$ can be utilized in-situ in the core of the nuclear reactor or later after its extraction from the spent nuclear fuel. The first option refers to the open while the second to the closed fuel cycle strategy. The advantages and disadvantages of the Th fuel cycle are presented in Table 1.

\begin{tabular}{|c|c|}
\hline Advantages & Disadvantages \\
\hline $\begin{array}{l}\text { - Thorium is } 3 \text { to } 4 \text { times more abundant than } \\
\text { uranium and thus can provide stable source } \\
\text { of energy for long period and complement } \\
\text { U-Pu fuel cycle, } \\
\text { - The Th-U fuel cycle is characterized by the } \\
\text { lower production of plutonium and long-live } \\
\text { actinides contributing significantly to the } \\
\text { radiotoxicity of the spent nuclear fuel, } \\
\text { - ThO } \mathrm{O}_{2} \text { fuel has better in-pile performance } \\
\text { because of the higher thermal conductivity } \\
\text { and lower coefficient of thermal expansion, } \\
\text { - The irradiated Th fuel is contaminated with } \\
\text { easily detectable }{ }^{232} \mathrm{U} \text {, which makes such } \\
\text { fuel easily detectable, } \\
\text { - High oxidation resistance of ThO } \mathrm{T}_{2} \text { facilitates } \\
\text { interim storage and final disposal, } \\
\text { - The transition to Th-U fuel cycle could be } \\
\text { done through the usage of weapons grade } \\
\text { plutonium. }\end{array}$ & $\begin{array}{l}\text { - }{ }^{232} \mathrm{Th} \text { provides inherent safety mechanism } \\
\text { similarly to }{ }^{238} \mathrm{U} \text { but its resonance integral is } \\
\text { about one third lower, } \\
\text { The much higher sintering temperature is } \\
\text { required to produce high density } \mathrm{ThO}_{2} \text {, } \\
\mathrm{ThO}_{2} \text { fuel do not dissolve easily in nitric acid, } \\
\text { which makes it reprocessing more difficult, } \\
\text { which could be considered also as an } \\
\text { advantage considering proliferation } \\
\text { resistance, } \\
\text { The irradiated Th fuels contain significant } \\
\text { amount of gamma emitting }{ }^{232} \mathrm{U} \text {, which } \\
\text { follows to the significant buildup of radiation } \\
\text { dose during storage or reprocessing, } \\
\text { The }{ }^{233} \mathrm{~Pa} \text { has half-life of } 27 \text { days and thereby } \\
\text { spent Th fuel requires longer cooling time, } \\
\text { The }{ }^{233} \mathrm{~Pa} \text { is the strong neutron absorber } \\
\text { deteriorating neutron economy, } \\
\text { Likelihood of using }{ }^{233} \mathrm{U} \text { for nuclear weapon, } \\
\text { Need of many costly researches and licensing } \\
\text { processes before starting industrial use e.g. } \\
\text { the development of THOREX process. }\end{array}$ \\
\hline
\end{tabular}

Table 1. The advantages and disadvantages of the Th fuel cycle.

There are two options for use of thorium in the PWRs. The first option, called heterogeneous approach, assumes using the mixture of thorium and uranium oxides within each fuel rod. The second one considers placing thorium and uranium fuel in separated regions, called the blanket and the seed, respectively. The heterogeneous design is far better for the effective conversion of ${ }^{232} \mathrm{Th}$ into fissile ${ }^{233} \mathrm{U}$. This approach once again considers two different concepts: Seed-Blanket Unit (SBU) and the Whole Assembly Seed and Blanket (WASB). The SBU represents the fuel assembly that consists of two separates fuel zones namely, enriched uranium seed in the center and thorium blanket around it. Another concept of heterogeneous fuel design is the WASB, which considers two different types of assemblies, one consisting of seed fuel rods and the second consisting of blanket fuel rods. Both are the size of standard PWR fuel assembly and they are arranged in the core centre in the checkerboard array. Both designs consider open fuel cycle, which means that ${ }^{233} \mathrm{U}$ is 
continuously produced and burned in the blanket and the fuel is not recycled afterwards for extraction of plutonium and minor actinides. In the study the WASB approach was introduced into the 4-loop Westinghouse nuclear reactor core.

\section{The Westinghouse 4-loop plant}

The numerical model of the Westinghouse 4-loop reactor was used in the presented study [3]. The reactor pressure vessel (RPV) has cylindrical shape with the hemispherical bottom and the upper head. The bottom head is welded to the cylindrical body, whilst the upper one is bolted, which enables its removal during outages in the reactor operation for refueling or inspection. The thickness of the cylindrical body equals about $21.6 \mathrm{~cm}$, of the upper head about $16.5 \mathrm{~cm}$ and of the lower head about $14 \mathrm{~cm}$. The high of the vessel is about $13 \mathrm{~m}$, the diameter about $4.8 \mathrm{~m}$ and the weight amounts to approximately 410 metric tons without internals. The design pressure between $17.0-17.5 \mathrm{MPa}$ and temperature between $340-350^{\circ} \mathrm{C}$ characterize the Western-type vessels and these parameters stand for the main design criteria of the RPV.

The nuclear reactor core is located in the center of the RPV and consists of the array of the fuel, moderator and control elements. The equivalent diameter of the reactor core in case of the 4-loop Westinghouse plant equals about $340 \mathrm{~cm}$. The high of the core is equivalent to the height of the fuel sub-assembly, and is about $400 \mathrm{~cm}$. The active height defined as the cumulative length of the pellets in the fuel pin equals $366 \mathrm{~cm}$. The 193 fuel sub-assemblies of the design $17 \times 17$ are comprised in the reactor core. Each fuel sub-assembly contains 289 location for 264 fuel pins, 24 locations for control rods guide tubes and one location for the instrument thimble. The total weight of the $\mathrm{UO}_{2}$ fuel located in the reactor core equals about 100 tons, of which 90 tons of heavy metal. The cumulative weight of the structural materials equals about 35 tones, of which zirconium cladding of the fuel pins about 25 tones. Remaining 10 tones are attributed to the weight of the stainless steel elements of the fuel subassembly and zirconium spacers. Thus, the total weight of the core is of about 135 tones.

\section{PWR in-core fuel management}

The design of the in-core fuel management is one of the most complicated tasks in the reactor core design. The minimum as possible fuel cycle costs together with the whole fulfilment of the thermal and nuclear constrains on the reactor core performances assure the effective and safe reactor operation. Before the reactor start-up one must take a decision about initial core loading pattern, reloading patterns, location and total loading of the burnable poison, type of the fuel and control rods, refueling schedules as well as predict the fuel burnup and isotope buildup (e.g. plutonium). All these decisions are strictly coupled with the core neutronics, core thermo-hydraulics, reactivity control and operational requirements. The incore fuel management, which cope with all these is one of the most difficult areas of the reactor core design[7, 8].

In general, the complete reactor fuel cycle consist of separate reactor cycles. That is periods between partial core refueling. At the beginning of such a period only some fuel subassemblies are discharged and replace by the fresh fuel. The remaining fuel sub-assemblies are shuffled to the other irradiation positions. The group of the fuel sub-assemblies having the same average enrichment, loaded into the reactor core for the first time is denoted as a fuel region, whereas the fuel sub-assemblies having the same enrichment and experiencing the same burnup history in the fuel region are called fuel batch. Usually, in case of the standard PWR reactors without Th component, the $1 / 3$ of the core is refueled on the yearly basis. However, the duration of the reactor cycle may vary from about 6 months even to 48 
months. The shorter refueling periods are not foreseen from the economical point of view because during the refueling the reactor is not in operation. Additionally, some fresh subassemblies may contain burnable poison, which further complicates the core optimization [9]. Moreover, the core designer must take into account safety limits on maximum discharged burnup, maximum moderator temperature coefficient, pressure vessel exposure, maximum power peaking and so on. Therefore, the design of the optimal core loading pattern is the complex non-linear combinatory problem with the high design space investigated by many scientific teams all over the world $[10,11,12]$.

\section{Numerical model}

The 3D model of the 4-loop Westinghouse plant was developed for the numerical simulation. The model contains the heterogenous reactor core as well as reactor pressurized vessel and its internals including control rods (see Fig. 1). The geometry and material composition of the structural components were reconstructed using available to public design data of the Westinghouse reactors $[3,13,14]$. The simulations were performed using the Monte Carlo Continuous Energy Burnup Code (MCB) developed at the AGH University, Faculty of Energy and Fuels, Department of Nuclear Energy. The MCB code is equipped in the material handling functions, which allow material shuffling, reloading, removal, admixing etc.. The JEFF3.1 cross section libraries were used for the numerical simulations. The simulations were performed using supercomputer Prometheus available in the Pl Grid Infrastructure and located at Academic Computer Centre CYFRONET AGH [15].

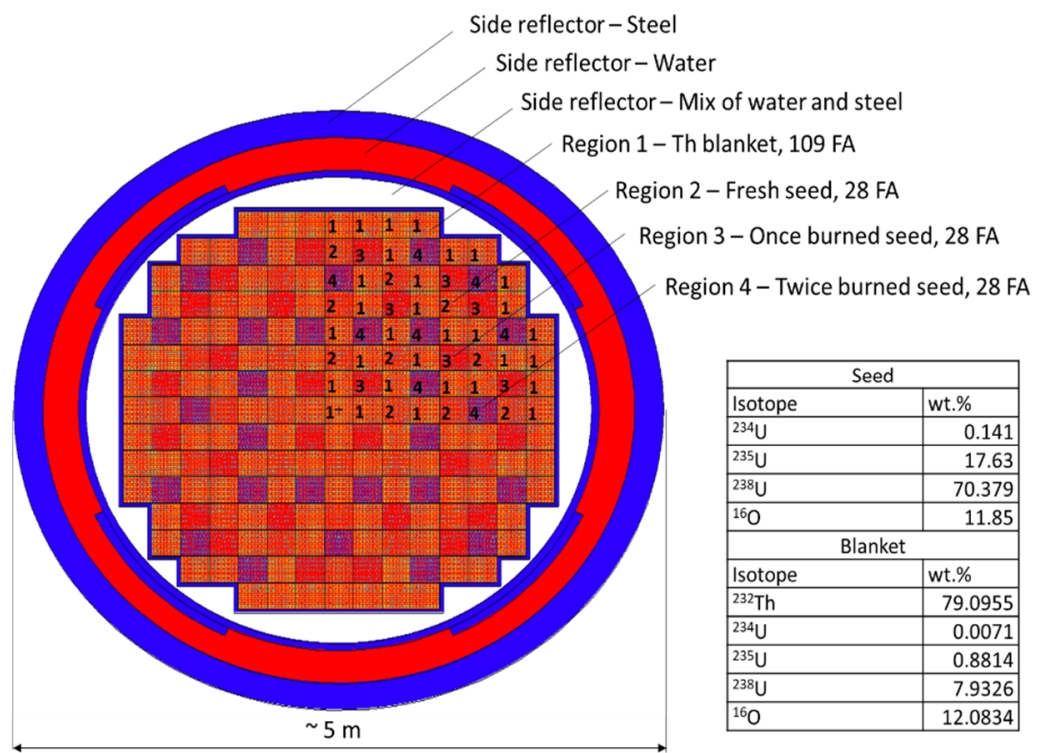

Fig. 1. Visualization of the reactor model and fuel isotopic composition with the numbering of fuel assemblies in the regions fore one core quarter.

For the introduction of Th fuel the reactor core was divided into 4 fuel regions presented in Fig. 1. The first fuel region contains Th blanket fuel. The remining three regions contain enriched uranium fuel.The geometry of the fuel assembly as well as of the fuel rod is consistent with the geometry of the standard $17 \times 17$ PWR fuel assembly. The blanket thorium rods contain mix of $\mathrm{ThO}_{2}(90 \mathrm{wt} . \%)$ and $\mathrm{UO}_{2}(10 \mathrm{wt} . \%)$ enriched to $10 \%{ }^{235} \mathrm{U}$ and density 
$10.302 \mathrm{~g} / \mathrm{cm}^{3}$. The seed fuel contains $\mathrm{UO}_{2}$ at density and $9.403 \mathrm{~g} / \mathrm{cm}^{3}$ and enrichment $20 \%$.

Table 2 shows the fresh mass of heavy metal

Table 2. Fresh fuel mass.

\begin{tabular}{|c|c|c|c|c|c|}
\hline \multirow{2}{*}{ Isotope } & \multicolumn{5}{|c|}{ Heavy Metal Mass [g] } \\
\cline { 2 - 6 } & R1 Blanket & R2 Seed 1 & R3 Seed 2 & R4 Seed 3 & Total \\
\hline Th232 & $3.99 \mathrm{E}+07$ & NA & NA & NA & $3.99 \mathrm{E}+07$ \\
\hline U234 & $3.58 \mathrm{E}+03$ & $2.00 \mathrm{E}+04$ & $2.00 \mathrm{E}+04$ & $2.00 \mathrm{E}+04$ & $6.36 \mathrm{E}+04$ \\
\hline U235 & $4.44 \mathrm{E}+05$ & $2.50 \mathrm{E}+06$ & $2.50 \mathrm{E}+06$ & $2.50 \mathrm{E}+06$ & $7.95 \mathrm{E}+06$ \\
\hline U238 & $4.00 \mathrm{E}+06$ & $9.98 \mathrm{E}+06$ & $9.98 \mathrm{E}+00$ & $9.98 \mathrm{E}+06$ & $2.40 \mathrm{E}+07$ \\
\hline
\end{tabular}

Table 3. In-core management schema for seed fuel.

\begin{tabular}{|c|c|c|c|c|c|c|}
\hline Cycle & \multicolumn{3}{|c|}{ Begining of cycle } & \multicolumn{3}{c|}{ End of cycle } \\
\hline 1 & $1 \mathrm{~F}$ & $2 \mathrm{~F}$ & $3 \mathrm{~F}$ & $1 \mathrm{I}$ & $2 \mathrm{I}$ & $3 \mathrm{I}$ \\
\hline 2 & $4 \mathrm{~F}$ & $2 \mathrm{I}$ & $3 \mathrm{I}$ & $4 \mathrm{I}$ & $2 \mathrm{II}$ & $3 \mathrm{II}$ \\
\hline 3 & $5 \mathrm{~F}$ & $4 \mathrm{I}$ & $3 \mathrm{II}$ & $5 \mathrm{I}$ & $4 \mathrm{II}$ & $3 \mathrm{III}$ \\
\hline 4 & $6 \mathrm{~F}$ & $5 \mathrm{I}$ & $4 \mathrm{II}$ & $6 \mathrm{I}$ & $5 \mathrm{II}$ & $4 \mathrm{III}$ \\
\hline 5 & $7 \mathrm{~F}$ & $6 \mathrm{I}$ & $5 \mathrm{II}$ & $7 \mathrm{I}$ & $6 \mathrm{II}$ & $5 \mathrm{III}$ \\
\hline 6 & $8 \mathrm{~F}$ & $7 \mathrm{I}$ & $6 \mathrm{II}$ & $8 \mathrm{I}$ & $7 \mathrm{II}$ & $6 \mathrm{III}$ \\
\hline 7 & $9 \mathrm{~F}$ & $8 \mathrm{I}$ & $7 \mathrm{II}$ & $9 \mathrm{I}$ & $8 \mathrm{II}$ & $7 \mathrm{III}$ \\
\hline 8 & $10 \mathrm{~F}$ & $9 \mathrm{I}$ & $8 \mathrm{II}$ & $10 \mathrm{I}$ & $9 \mathrm{II}$ & $8 \mathrm{III}$ \\
\hline 9 & $11 \mathrm{~F}$ & $10 \mathrm{I}$ & $9 \mathrm{II}$ & $11 \mathrm{I}$ & $10 \mathrm{II}$ & $9 \mathrm{III}$ \\
\hline 10 & $12 \mathrm{~F}$ & $11 \mathrm{I}$ & $10 \mathrm{II}$ & $12 \mathrm{I}$ & $11 \mathrm{II}$ & $10 \mathrm{III}$ \\
\hline 11 & $13 \mathrm{~F}$ & $12 \mathrm{I}$ & $11 \mathrm{II}$ & $13 \mathrm{I}$ & $12 \mathrm{II}$ & $11 \mathrm{III}$ \\
\hline
\end{tabular}

F - Fresh fuel, I - once burned fuel, II - twice burned fuel, III - thrice burned fuel

The fuel irradiation was modelled for 11 reactor cycles with the length of 540 days each at nominal power of $3423 \mathrm{MW}_{\text {th }}$. In addition the irradiation step in the middle of the irradiation cycle was introduced to show the fuel evaluation during one cycle. In the first three initial cycles reactor core reaches the equilibrium state. The Th blanket fuel placed at the reactor peripheries is neither reloaded nor shuffled during assumed reactor operation. Table 3 presents the shuffling schema for the seed fuel. The total load of the seed fuel equals 13 batches of 28 fuel assemblies each. The fresh three batches (84 FA) are introduce into the core at the beginning of operation. After first cycle the batch $\mathrm{nr} 1$ is reloaded and replaced by the fresh fuel batch $\mathrm{nr}$ 4. The remining two batches (2 and 3) stay in the core without shuffling. After second reactor cycle the batch number 4 is replaced by the fresh batch nr 5 and shuffled to the position of the twice burned batch $\mathrm{nr} 2$. The batch $\mathrm{nr} 3$ stays in the core at the defined positions. After third reactor cycle the batch $\mathrm{nr} 5$ is replaced by the fresh batch $\mathrm{nr}$ 6 and shuffled to the position of the twice burned batch $\mathrm{nr} 4$. The twice burned batch number 4 is shuffled to the positions of the thrice burned batch $\mathrm{nr}$ 3. The thrice burned batch number 3 is reloaded from the reactor core. At the beginning of the fourth reactor cycle the equilibrium state is achieved, i.e. there are 24 fresh, 24 once burned and 24 twice burned fuel assemblies in the reactor core. The foreseen time of the Th blanket irradiation equals 9 reactor 
cycles of the length 18 months each, but in my calculations I extended this time to 11 rector cycles to investigate further fuel behavior. The reactivity control is not included in the simulations. The control rods are fully withdrawn above reactor core, fuel does not contain burnable poison, there is no boron dissolved in the cooling water. The reactivity control is foreseen for the further studies after adjustment of the final core configuration of WASB. The following calculations show feasibility of the proposed in-core management patter using the available numerical tools, developed numerical model and methods.

\section{Results}

\subsection{Blanket fuel}

Fig. 2 shows the evolution of the fissile isotopes in the blanket fuel. Initially, the concentration of ${ }^{235} \mathrm{U}$ goes down due to is ongoing burnup during reactor operation. However, at about 2000 days it starts slowly increasing. The effect is related to the production of ${ }^{235} \mathrm{U}$ in the series of subsequent neutron capture reactions on the already produced ${ }^{233} \mathrm{U}$ and ${ }^{234} \mathrm{U}$. The concentration of ${ }^{233} \mathrm{U}$ initially increase and reaches maximum at about 2000 days. Then it starts slight decreasing. The fissile ${ }^{239} \mathrm{Pu}$ rapidly increases at the beginning of operation and reaches maximum at about 4000 days. The ${ }^{241} \mathrm{Pu}$ achieves equilibrium concentration at about 4000 days of irradiation. The drop in the concentration of ${ }^{235} \mathrm{U}$ is compensated by the increase in concentration of ${ }^{233} \mathrm{U}$. It means that in the blanket region the primary fuel is replaced by the bred secondary fuel. In addition the final lumped concentration of ${ }^{233} \mathrm{U},{ }^{239} \mathrm{Pu}$ and ${ }^{241} \mathrm{Pu}$ $(\sim 700 \mathrm{~kg})$ is about one order of magnitude higher than the initial concentration of ${ }^{235} \mathrm{U}(\sim 70$ $\mathrm{kg}$ ). Thus, the process of the net fissile material breeding take place in the blanket fuel. Fig. 3 present the evolution of the fertile material i.e. ${ }^{232} \mathrm{Th}$ and ${ }^{238} \mathrm{U}$. In the blanket fuel the ${ }^{232} \mathrm{Th}$ goes down due to its conversion to ${ }^{233} \mathrm{U}$ and further to higher actinides. The decrease in ${ }^{232} \mathrm{Th}$ during considered reactor operation is about 5.6 tones. The ${ }^{238} \mathrm{U}$ is converted to ${ }^{239} \mathrm{Pu}$ and further to ${ }^{241} \mathrm{Pu}$ and higher actinides and its decrease during reactor operation is about 2 tones. The decrees of both isotopes in the blanket shows a linear behaviour. However, the pace of ${ }^{232} \mathrm{Th}$ decrease is much faster.

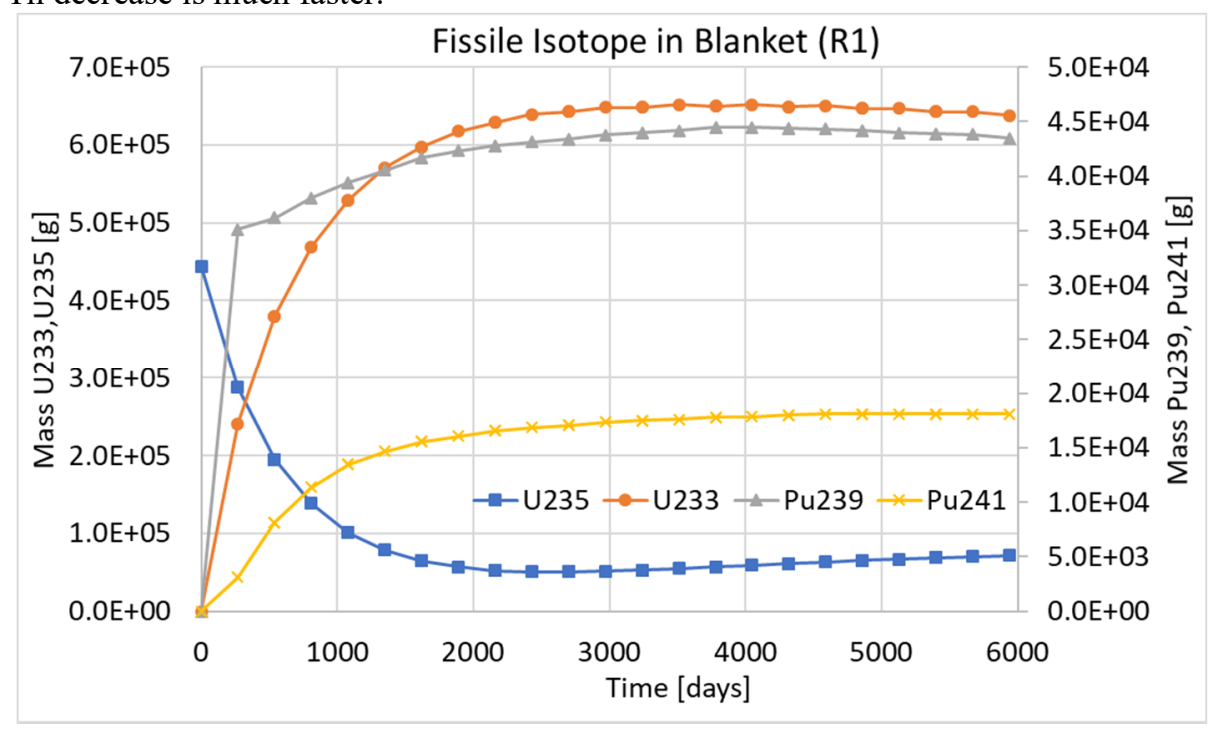

Fig. 2. Time evolution of the fissile isotopes in the blanket. 


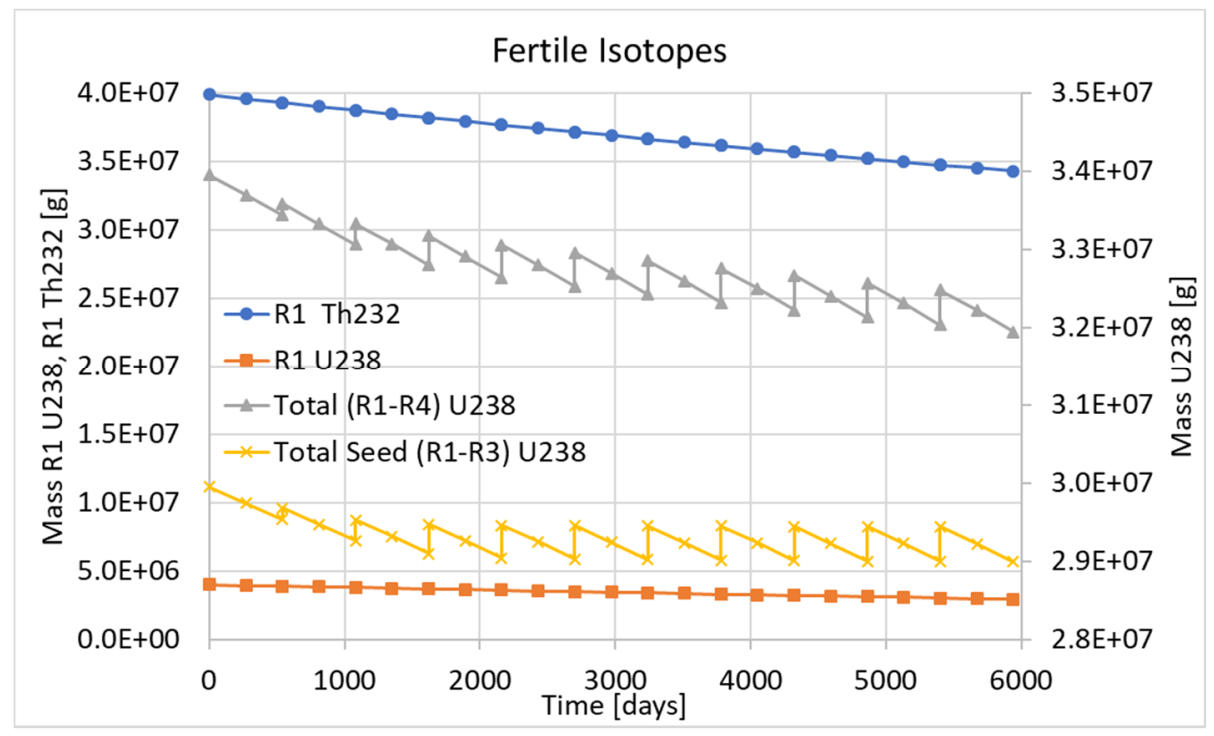

Fig. 3. Time evolution of fertile isotopes.

\subsection{Seed fuel}

Fig. 4 presents the evolution of ${ }^{235} \mathrm{U}$, which is the basic fissile isotopes in the seed fuel. The concentration of ${ }^{235} \mathrm{U}$ decreases during the reactor cycle due to its burnup and increases at the beginning of each reactor cycle due to the introduction of the fresh fuel batch. In the first three reactor cycles the reactor core reaches the equilibrium state. Therefore, the initial total load of ${ }^{235} \mathrm{U}$ at the beginning of operation is higher than the maximum ${ }^{235} \mathrm{U}$ concentration in the equilibrium state. The longer particular fuel batch is irradiated the lower is the final concentration of ${ }^{235} \mathrm{U}$ in the batch. It could be seen in Fig. 4 that the final concentration of ${ }^{235} \mathrm{U}$ in the first region corresponds to its initial concentration in the second region and the final concentration in second region corresponds to the initial concentration in the third region. The effect is related to the fuel shuffling in the reactor core and also corresponds to other investigated isotopes $\left({ }^{239} \mathrm{Pu},{ }^{241} \mathrm{Pu},{ }^{238} \mathrm{U}\right)$. The time evolution of total ${ }^{235} \mathrm{U}$ and ${ }^{235} \mathrm{U}$ in the seed region is similar because the concentration of ${ }^{235} \mathrm{U}$ in blanket is lower than in seed region. In addition, the burnup of ${ }^{235} \mathrm{U}$ in the blanket region is quite fast and thus its influence on the total evolution in the equilibrium state is low. In the analysis I consider time evolution of two fissile plutonium isotopes i.e. ${ }^{239} \mathrm{Pu}$ and ${ }^{241} \mathrm{Pu}$, see Fig. 5 and Fig. 6. The concentration of both isotopes increases due to its breading from fertile isotope ${ }^{238} \mathrm{U}$. The longer fuel irradiation the lower concentration growth of both Pu isotopes in each rector cycle because the fission of ${ }^{235} \mathrm{U}$ is compensated by the fission of built-up ${ }^{239} \mathrm{Pu}$ and ${ }^{241} \mathrm{Pu}$. In addition, its production decreases because of lower conversion of ${ }^{238} \mathrm{U}$. However, the concentration of ${ }^{239} \mathrm{Pu}$ and ${ }^{241} \mathrm{Pu}$ increases at the end of each reactor cycle. This means that the equilibrium concentration of this isotopes is not reached during the considered reactor operation. The drop of $\mathrm{Pu}$ concentration at the end of each reactor cycle in the equilibrium state is caused by its discharge from the reactor core during refueling. The evolution of total concentration of both isotopes is driven by the breading in seed as well as in blanket regions unlike ${ }^{235} \mathrm{U}$. The concentration of ${ }^{239} \mathrm{Pu}$ is larger than the concentration of ${ }^{241} \mathrm{Pu}$ because the transmutation and decay chain following to the second isotopes is longer. Fig. 2 and Fig. 7 depict evolutions of fertile ${ }^{238} \mathrm{U}$. The concentration of ${ }^{238} \mathrm{U}$ goes down due to its conversion to higher actinides especially ${ }^{239} \mathrm{Pu}$ and ${ }^{241} \mathrm{Pu}$. The drop in ${ }^{238} \mathrm{U}$ for each fuel batch is almost linear during all reactor cycles. The increase in its concentration at each beginning of cycle 
is caused by the fuel reloading. The conversion of ${ }^{238} \mathrm{U}$ to higher actinides decreases in function of irradiation time i.e. the highest conversion is in the first irradiation cycles of the considered fuel batch and the lowest in the third irradiation cycles of the considered fuel batch.

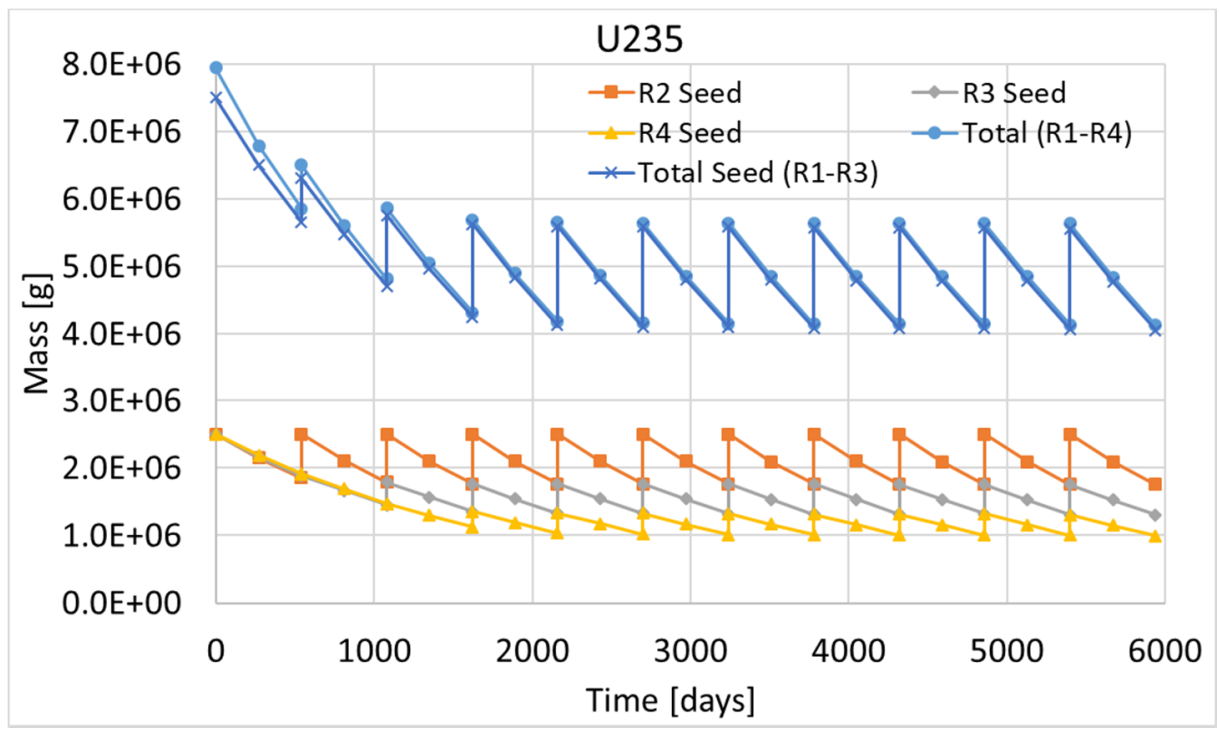

Fig. 4. Time evolution of ${ }^{235} \mathrm{U}$ in seed fuel.

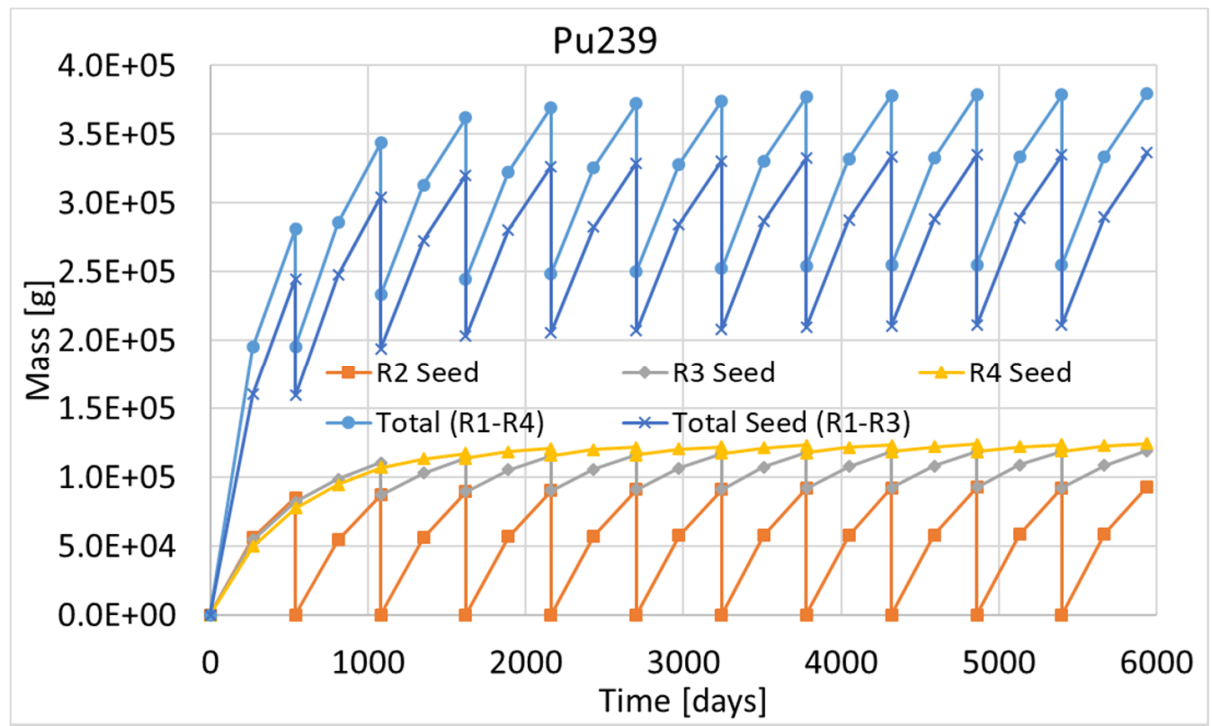

Fig. 5. Time evolution of ${ }^{239} \mathrm{Pu}$ in seed fuel. 


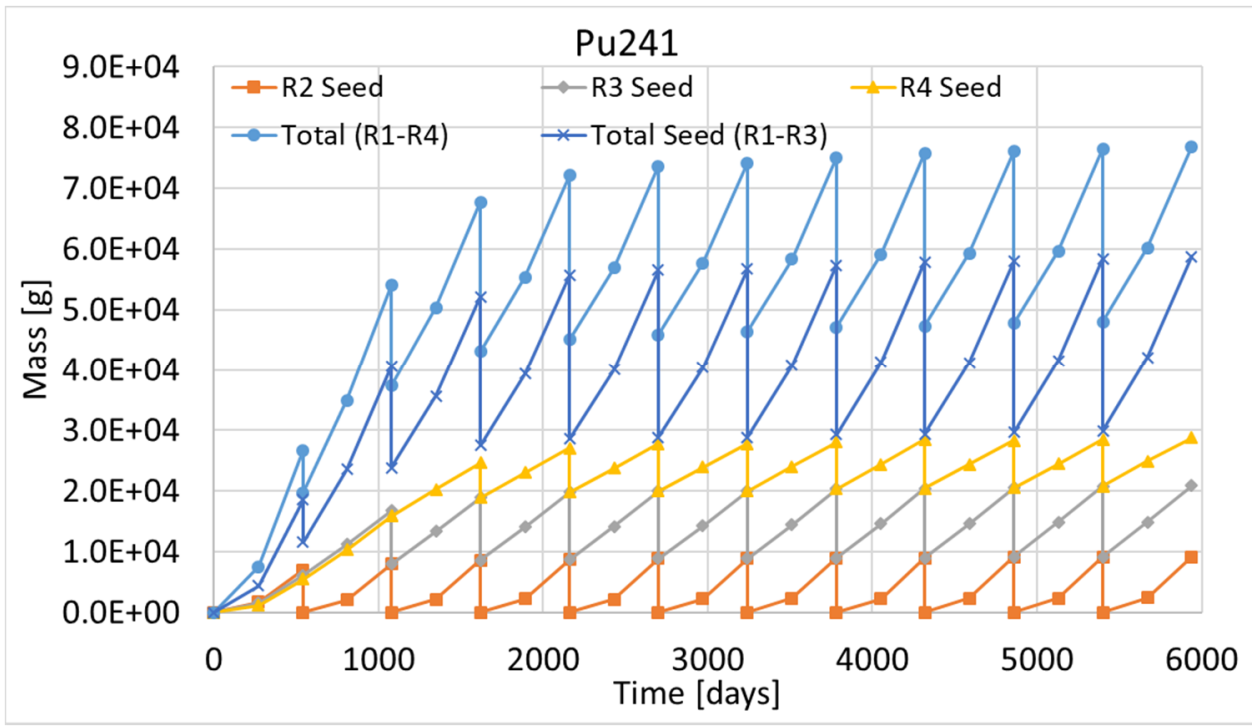

Fig. 6. Time evolution of ${ }^{241} \mathrm{Pu}$ in seed fuel.

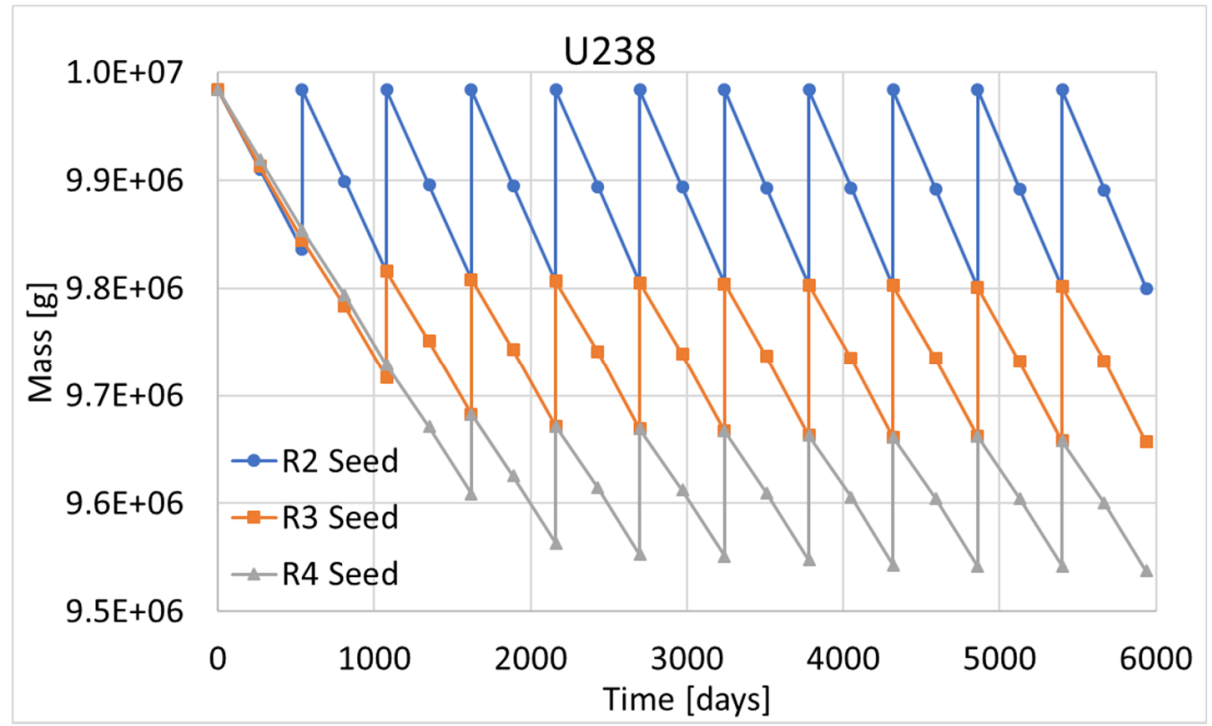

Fig. 7. Time evolution of ${ }^{238} \mathrm{U}$ in seed fuel.

\section{Conclusions}

The MCB code was used for the numerical simulations of the PWR reactor with the thorium fuel. The new in-core loading patter was introduced to the developed numerical model. The fuel shuffling during 11 reactors cycles were simulated using processing cards available in the MCB code. The main physical effects related to the fuel burnup and to the formation of new isotopes in the neutron field were pointed out in the study. The developed method as well as numerical model seems to be able to reconstruct physics of the more advanced numerical models of the PWR reactor with the reactivity control. For this reason, in my future research, the modification of the PWR core arrangement will consider change 
in the blanket fuel rod geometry, introduction of burnable poison, dissolution of born in cooling water and adjustment of the final enrichment in ${ }^{235} \mathrm{U}$. The numerical model of the PWR reactor with the higher spatial resolution should be developed to consider all aforementioned improvements. The introduction of Th component to the standard PWR changes operation condition during its lifetime. Therefore, the general parametric study showing the optimal in-core loading patter and fuel shuffling should be performed.

Acknowledgements: The research was partially supported by PL Grid Infrastructure available at the Academic Computer Centre CYFRONET AGH. In addition, partial financial support of this study by the Polish Ministry of Science and Higher Education, under the grant agreement 11.11.210.377, is kindly acknowledged.

\section{References}

1. M. Oettingen, J. Cetnar, T. Mirowski, CSCI, 16, 329-350 (2015)

2. J. Cetnar, ANN NUCL ENERGY, 33, 640-645 (2006)

3. Westinghouse Electric Corporation Water Reactor Divisions, Marketing Manager Nuclear Operations Division P.O. Box 355 Pittsburgh, Pennsylvania 15230, The Westinghouse pressurized water reactor nuclear power plant (1984)

4. International Atomic Energy Agency, Thorium fuel cycle - Potential benefits and challenges, Vienna, (2005)

5. S. F. Ashley, B. A. Lindley, G. T. Parks, W. J. Nuttall, R. Gregg, K. W. Hesketh, U. Kannan, P. D. Krishnani, B. Singh, A. Thakur, M. Cowper, A. Talamo, ANN NUCL ENERGY, 69, 314-330 (2014)

6. T. Ault, S. Krahn, A. Croff, ANN NUCL ENERGY, 110, 726-738 (2017)

7. P. Stanisz, M. Oettingen, J. Cetnar, NUCL ENG DES, 301, 341-352 (2016)

8. J. Maiorino, G. L. Stefani, J. M. L. Moreira, P. C. R. Rossi, T. A. Santos, ANN NUCL ENERGY, 102, 47-55 (2017)

9. M. Oettingen, J. Cetnar, NUCL ENG DES, 273,359-366 (2014)

10. L. P. Tucker, S. Usman ANN NUCL ENERGY, 111, 163-175 (2018)

11. M.S. Kazimi, K. R. Czerwinski, M. J. Driscoll, P. Hejzla, J. E. Meyer, On the use of thorium in light water reactors, MIT-NFC-TR-016, Cambridge, (1999)

12. C. Wah Lau, Improved PWR Core Characteristics with Thorium-containing Fuel, ISBN 978-91-7385-990-5, Division of Nuclear Engineering, Department of Applied Physics, Chalmers University of Technology, Goteborg, (2014)

13. D. Wang, Optimization of a seed and blanket Thorium uranium fuel cycle for pressurized water reactor, Massachusetts Institute of Technology, (2003)

14. M. Oettingen, Validation of fuel burnup modelling with MCB Monte Carlo system using destructive assay data from Ohi-2 PWR, ISBN: 978-83-7464-806-6, (2016)

15. Academic Computer Centre CYFRONET AGH, http://www.cyfronet.krakow.pl/ 